\title{
The prevalence of chronic pain in Canada
}

\author{
Donald Schopflocher $\mathrm{PhD}^{1,2}$ Paul Taenzer $\mathrm{PhD}^{3}$, Roman Jovey MD
}

\author{
D Schopflocher, P Taenzer, R Jovey. The prevalence of chronic pain \\ in Canada. Pain Res Manage 2011;16(6):445-450.
}

BACKGROUND: While chronic pain appears to be relatively common, published population prevalence estimates have been highly variable, partly due to differences in the definition of chronic pain and in survey methodologies.

OBJECTIVES: To estimate the prevalence of chronic pain in Canada using clear case definitions and a validated survey instrument.

METHODS: A telephone survey was administered to a representative sample of adults from across Canada using the same screening questionnaire that had been used in a recent large, multicountry study conducted in Europe.

RESULTS: The prevalence of chronic pain prevalence for adults older than 18 years of age was $18.9 \%$. This was comparable with the overall mean reported using identical survey questions and criteria for chronic pain used in the European study. Chronic pain prevalence was greater in older adults, and females had a higher prevalence at older ages compared with males. Approximately one-half of those with chronic pain reported suffering for more than 10 years. Approximately one-third of those reporting chronic pain rated the intensity in the very severe range. The lower back was the most common site of chronic pain, and arthritis was the most frequently named cause.

CONCLUSIONS: A consensus is developing that there is a high prevalence of chronic pain within adult populations living in industrialized nations. Recent studies have formulated survey questions carefully and have used large samples. Unfortunately, a substantial proportion of Canadian adults continue to live with chronic pain that is longstanding and severe.

Key Words: Chronic pain; Prevalence; Statistics; Survey

\section{La prévalence de la douleur chronique au Canada}

HISTORIQUE : La douleur chronique semble relativement courante, mais les évaluations publiées sur sa prévalence en population sont hautement variables, en partie à cause des différences dans la définition de la douleur chronique et la méthodologie des enquêtes.

OBJECTIFS : Évaluer la prévalence de la douleur chronique au Canada, au moyen de définitions de cas claires et d'un instrument d'enquête validé.

MÉTHODOLOGIE : Un échantillon représentatif d'adultes du Canada a participé à un sondage téléphonique au moyen du même questionnaire de dépistage que celui qui a été récemment utilisé dans une vaste étude menée dans plusieurs pays d'Europe.

RÉSULTATS : La prévalence de la douleur chronique chez les adultes de plus de 18 ans s'élevait à $18,9 \%$, ce qui est comparable à la moyenne globale déclarée au moyen de questions de sondage et de critères de douleur chronique pareils à ceux utilisés dans l'enquête européenne. La prévalence de la douleur chronique était plus élevée chez les adultes plus âgés, et les femmes présentaient une prévalence plus élevée à un âge avancé que les hommes. Environ la moitié des personnes souffrant de douleurs chroniques déclaraient en être incommodées depuis plus de dix ans. Environ le tiers de celles qui signalaient des douleurs chroniques en évaluaient l'intensité dans la plage très grave. La région lombaire était le principal foyer de douleur chronique et l'arthrite, la cause la plus invoquée.

CONCLUSIONS : Un consensus se dégage selon lequel il existe une forte prévalence de douleur chronique chez les populations adultes qui habitent dans des pays industrialisés. Les récentes études contiennent des questions soigneusement formulées et ont été administrées à de vastes échantillons. Malheureusement, une forte proportion d'adultes canadiens continue d'endurer des douleurs chroniques importantes et de longue date.

Nickel and Raspe (6) conducted a qualitative systematic review on the epidemiology and use of services in treating CP that included 17 epidemiological studies (including many also reviewed by Verhaak et al [5]). The prevalence estimates for CP ranged from 7\% to $55.2 \%$. These authors also extracted information about demographic variables from individual studies. The frequency of $\mathrm{CP}$ appeared to increase with age, with a peak between 45 and 65 years of age, and higher prevalence was found among women. Because of the heterogeneity in the studies in population characteristics, modes of data collection, and definitions of CP, the authors chose not to combine results into a single prevalence estimate.

Ospina and Harstall (7) conducted an additional systematic review on 13 studies published between 1991 and 2002. Prevalence estimates of CP ranged from $11.5 \%$ to $55.2 \%$. Studies were examined according to population characteristics, sample size, response rate, but also according to the definition of $\mathrm{CP}$, in the hope of characterizing prevalence estimates according to the properties of the studies. Twelve studies had been conducted in nine different countries on four continents, and one was multinational, with collaborating centres in 16 countries on four continents. Eleven studies surveyed the general population and two studies surveyed populations receiving care in primary care settings. The International Association for the Study of Pain (IASP)

While CP is known to be relatively common, published population prevalence estimates have been highly variable. In a systematic review of epidemiological studies of CP among adults, Verhaak et al They suggested that this variability might be $40 \%$ ) across 15 studies. population and mode of data collection. Thus, 13 studies were general population surveys, while two were primary health care surveys, and the data collection methods used in the individual studies included telephone survey (three studies), postal questionnaire (six studies), interview (three studies) and expert assessments (three studies).

${ }^{1}$ Centre for Health Promotion Studies, School of Public Health, University of Alberta; ${ }^{2}$ Faculty of Nursing, University of Alberta, Edmonton;

${ }^{3}$ Alberta Health Services, Calgary Pain Service, Calgary, Alberta; ${ }^{4}$ CPM Centres for Pain Management Eु Physician Director, Addictions and

Concurrent Disorders Centre, Credit Valley Hospital, Mississauga, Ontario

Correspondence: Dr Donald Schopflocher, 7-36 UT, 8303-112 Street, Edmonton, Alberta T6G 2T4. Telephone 780-492-7112,

fax780-492-2551,e-mail donald.schopflocher@ualberta.ca 
provides one of the most frequently referenced definitions, defining $\mathrm{CP}$ as pain that persists beyond the normal tissue healing time (usually taken to be three months) (8). However, only seven studies provided a definition of CP that could be considered to be comparable with the IASP definition. These differences did not account for the variability in the prevalence estimates across studies.

In an extension to the Ospina and Harstall study using the same search criteria (9), two additional large scale international surveys were located. Breivik et al (10) conducted a two-stage telephone survey about CP across 15 European countries and Israel. A total of 46,394 individuals (of 67,733 contacted) participated in the first survey. Nineteen per cent of adults 18 years of age or older (mean age 49.9 years) reported experiencing moderate to severe CP lasting more than six months, as defined by ratings of 5 or greater on a 10-point numerical rating scale. Prevalence across countries still differed widely (range: Spain $12 \%$ to Norway 30\%). Demyttenaere et al (11) asked questions about chronic neck and back pain as part of a face-to-face administration of the Composite International Diagnostic Interview used to examine mental health. The survey was performed in 17 countries in the Americas, Europe, the Middle East and Africa, Asia, and the South Pacific. A subsample of 42,697 (from the total of 85,088 respondents) completed questions about the presence of, or treatment for, chronic back or neck problems in the previous 12 months. Prevalence according to country also differed widely in this study (range: Colombia 9.7\% to Ukraine $42.2 \%$ ), although there was also a wide range of average ages across the countries ( 35.2 to 51.4 years). These studies strongly suggest that CP prevalence also has a cultural component.

\section{CP PREVALENCE IN CANADA}

Prevalence estimates have also varied across studies in Canada. In an early Canadian report, Crook et al (12) estimated that 16\% of individuals from a sample of 500 households on the roster of a group family practice had suffered pain within the previous two weeks, approximately two-thirds of these individuals reporting persistent rather than temporary pain.

Birse and Lander (13) reported on a small random digit dial telephone survey of 410 adults with an average age of 40.8 years from Edmonton, Alberta. Of these, $40.4 \%$ responded positively to the question "Do you have or have you had since the past six months any pain or discomfort?" Females were $10 \%$ more likely to respond positively than males.

Moulin et al (14) surveyed 2012 adults older than 18 years of age from the general population by random digit dial survey. They asked 13 brief questions relating to the origin, duration, and intensity of $\mathrm{CP}$ conditions. Of these, $29 \%$ reported continuous or intermittent pain lasting six months or longer. Of these, $88 \%$ rated the intensity of their pain as 4 or higher on a 10-point scale. Prevalence increased with age from $22 \%$ in the 18 - to 34 -year-old age range, to $39 \%$ in the group 55 years of age and older. Females had a $4 \%$ higher prevalence rate than males.

Boulanger et al (15) used the same method and questionnaires three years later to survey 1055 adults older than 18 years of age from the general population. This time, $25 \%$ of the sample reported continuous or intermittent pain lasting six months or longer. Similar to the earlier survey, $88 \%$ rated the intensity of their pain as 4 or higher on a 10-point scale. Again, the prevalence increased with age from $17 \%$ in the 18 - to 34 -year-old age range, to $33 \%$ in the group 55 years of age and older, with females having a $5 \%$ higher prevalence rate than males. A larger proportion rated their pain as severe (51\%) compared with the earlier survey (32\%).

Tripp et al (16) report on a random digit dial telephone survey of 1067 southeastern Ontario residents who reported on pain intensity, activity limitation due to interference with activity, disability, and persistence as assessed by a Graded Chronic Pain Scale. Results were reported by gradations defined by cross-classifications of pain intensity, activity limitation and disability. Approximately 16\% reported high pain intensity with moderate or greater interference with life activity, while only $24 \%$ reported an absence of pain in the past six months. Approximately $49 \%$ of those reporting pain reported a persistence of at least 90 days in the previous six months, but this is an overall percentage, and the proportions by CP grade are not reported.

A number of studies have reported CP prevalence in Canada based on responses to the National Population Health Survey (NPHS), a longitudinal health survey of the general population, conducted by Statistics Canada. In this survey, CP is assessed using two questions based on the Health Utilities Index (17). The first asks about pain intensity on a 3-point scale, and the second about degree of activity limitation due to pain on a four-category scale. While these questions do ask about individuals' usual abilities, rather than short term states, there was no specific temporal criterion for duration or persistence of pain, so the answers to questions would not allow the conclusion that individuals meet the IASP definition of CP. Millar (18) presented a portrait of CP in Canada based on responses to the 1994 wave of the NPHS. Among 16,989 respondents 15 years of age and older from across Canada, 17\% reported some level of persistent pain, including approximately $11.9 \%$ who reported moderate or greater levels. An age gradient was discovered that ranged from $10 \%$ in the 15 - to 24-year-old group, to $35 \%$ in the 75 -year-old age group. Females, on average, reported $5 \%$ higher rates consistently at all ages. Schopflocher (19) presented detailed information from a large sample of Albertans about the prevalence and descriptive epidemiology of CP derived from the 1996 wave of the NPHS. In 1996, Alberta commissioned survey responses from an additional sample of Albertans 12 years of age and older (or four to 11 years of age as reported by a parent or proxy). The total sample size was 15,535 . This study used a crossclassification of the questions about pain intensity and degree of activity limitation due to pain to distinguish four levels (mild, mild to moderate, moderate, and severe) of CP. Overall, 3.95\% were consider to have mild CP, $2.58 \%$ to have mild to moderate CP, $2.35 \%$ to have moderate CP and $2.28 \%$ to have severe CP. The remaining $88.8 \%$ reported no pain. (The inclusion of children and/or youth will have the effect of lowering the apparent population prevalence from what it would be for an adult-only population) Age-sex relationships were also examined. The prevalence of pain increases markedly with age (from $<6 \%$ at age 18 to $18 \%$ at age 65 in males and 24\% in females), and females are more likely to suffer CP than are males at every age older than 18 years. Van Den Kerkhof et al (20) presented an analysis of an unreported number of respondents to the 1996 wave of the NPHS from across Canada who were 25 years of age or older. CP was defined using only the first pain question. Overall, the prevalence of CP was $15.1 \%$. Of these, $28.9 \%$ reported mild intensity, $54.4 \%$ reported moderate intensity, and the remaining $16.7 \%$ reporting severe intensity. Female $\mathrm{CP}$ prevalence was higher than male $\mathrm{CP}$ prevalence at each age, and increased steadily from $9.8 \%$ at ages 25 to 34 years, to $28.7 \%$ at 75 years of age and older. Male CP prevalence also increased steadily from $8.1 \%$ at 25 to 34 years of age, to $27.1 \%$ at 75 years of age or older. Rashiq and Dick (21) also reported an analysis of 69,345 respondents to the 1996 wave of the NPHS from across Canada who were 15 years of age or older. CP was also defined using only the first pain question. Overall, the CP prevalence was $14 \%$. (The inclusion of children and/or youth will have the effect of lowering the apparent population prevalence from what it would be for an adult-only population) Prevalence according to age and sex was the same as previously reported by Van Den Kerkhof et al (20), with the addition of a prevalence of $6.6 \%$ for the age category 15 to 24 years of age.

The variability among the Canadian estimates (from 16\% to 41\%), while slightly narrower than the ranges from systematic reviews reporting international data (5-7), was also most likely due to differences between studies in populations, samples, methods of data collection and definitions of CP.

In summary, there has been substantial variability in reported CP prevalence estimates that may be largely attributable, at least, to differences in study methods including the following: 


\section{TABLE 1}

\section{Prevalence estimates for chronic pain according to} successive criteria

\begin{tabular}{lc}
\hline & $\%$ (95\% Cl) \\
\hline Considers self as suffering from pain (S5) & $44.4(41.9-46.9)$ \\
For six months or more (S8) & $35.1(33.1-37.1)$ \\
Last suffered less than one month ago (S9) & $29.7(28.1-31.4)$ \\
Suffering several times a week or more (S10) & $24.9(23.4-26.3)$ \\
With an intensity last time of 5+ (on a 0-10 scale) (S11) & $18.9(17.8-20.0)$ \\
\hline
\end{tabular}

- the populations chosen for study (eg, general population versus primary care);

- mode of data collection;

- demographic characteristics of chosen participants including especially age but also including sex, income and levels of comorbidity;

- the specific questions asked and their use in defining CP; and

- cultural contexts and regional differences.

The single most important recommendation for the research agenda (5-7) has been to conduct concurrent, prospective epidemiological studies to estimate the CP prevalence using a well-defined population, clear case definitions, and well-validated and reliable data collection tools.

In the present study, we administered a survey to Canadian adults using the same screening questionnaire used by Brevik et al (10) and the same detailed criteria for establishing the presence of CP.

\section{METHODS}

\section{Design}

Two independent telephone surveys were conducted by Nanos Research, a Canadian market research company, using random-digit dialing in October 2007 and October 2008.

\section{Participants}

Participants were recruited from six separate regions in Canada. For each survey, 400 participants were recruited from each of Ontario and Quebec, and 300 were recruited from each of four other regions (Atlantic provinces, Prairie provinces, Alberta and British Columbia). Only participants who reported being 18 years of age or older, and reported suffering from pain from an illness, accident or medical condition (question S55) were included. Sample sizes for each survey were chosen so that the $95 \%$ CI for national estimates would be $\pm 2 \%$ or less. The allocation of sample to regions is sufficient to ensure that the CI would be $\pm 6 \%$ or less. The response rate for the 2007 survey was $22.0 \%$; the response rate for the 2008 survey was not available.

\section{Measures}

A screening questionnaire, similar to the one used by Brevik et al (10), was used. It consisted of 12 questions to assess the prevalence of $\mathrm{CP}$, age and sex of respondents, the duration and frequency of pain, the intensity of pain during the last episode, and the location and cause of the pain (Appendix). Questionnaire administration lasted approximately $5 \mathrm{~min}$.

\section{Analysis}

All data analysis was conducted using SPSS version 18 (IBM Corporation, USA) on an SPSS data file provided by Nanos Research.

\section{Data preparation}

Because the six regions differ dramatically in population, the survey was weighted to enable national prevalence estimates to be calculated. Poststratification adjustments were applied for six age groups (18 to 25,26 to 35,36 to 45,46 to 55,56 to 65 and 66 years of age and older) and two sex groups within each of the six regions. All population data were retrieved from population estimates for the fourth quarter of 2008 from Statistics Canada (22).
TABLE 2

Prevalence of chronic pain, Canada 2007 to 2008, according to region (18 years of age or older)

\begin{tabular}{ll}
\hline Region & $\%(95 \% \mathrm{Cl})$ \\
\hline Atlantic & $21.9(19.2-24.6)$ \\
Quebec & $15.7(3.7-17.7)$ \\
Ontario & $16.6(14.6-18.7)$ \\
Prairie & $19.6(17.0-22.1)$ \\
Alberta & $20.6(18.1-23.1)$ \\
British Columbia & $21.8(19.1-24.5)$ \\
Canada & $18.9(17.8-20.0)$ \\
\hline
\end{tabular}

Bootstrap weights were calculated to facilitate data analysis according to methods described by Yeo et al (23). These weights allowed consistent estimates of variability (standard errors and CIs) to be calculated in all analyses using bootstrap analysis procedures.

\section{Calculation of prevalence}

Because the number of adults older than 18 years of age in households in which no adults reported suffering from pain (question S3) was not recorded in the 2007 survey, these data were imputed from data collected in the 2008 survey, and the data from the two surveys were analyzed together. Also, the calculation of prevalence required assumption-based data imputation because a full household roster of individuals' age, sex and pain status was not collected. (First, this restricts the ability to estimate age- and sex-specific prevalence. The required assumptions are stringent: namely, that those individuals not interviewed both in no-pain households and in pain households had age, sex and pain status distributions identical to the respondents. Second, in estimating overall prevalence, the precision of estimates is lessened because region-specific weights were imputed for enumerated non-respondents but age-sex poststratification weights could not be applied. Third, while the pain status [ie, no pain] could be imputed for individuals in no pain households, the pain status of other household members in pain households [as enumerated in question S4] required imputation on the assumption that the same proportion of them would have had a particular pain status as those who answered the survey questions.)

\section{RESULTS}

Table 1 summarizes the estimated prevalence of CP according to whether individuals met successive criteria embedded within the questionnaire. Thus, more than $44 \%$ of individuals considered themselves as suffering from pain due to illness, accident or a medical condition. However, only approximately $19 \%$ of individuals met all of these criteria for suffering from CP.

Table 2 presents the prevalence estimates according to region. The Atlantic region had the highest prevalence of $\mathrm{CP}$, while Ontario and Quebec, the most populous provinces, had the lowest rates of CP. Because the CIs for all regions overlap the CI for the country as a whole, it is possible that the apparent differences between the regions were due to sampling variations.

Table 3 presents the prevalence estimates according to age group. Despite the caveats regarding the estimation of age specific rates of $\mathrm{CP}$ (see Calculation of prevalence), the data strongly suggest that rates of $\mathrm{CP}$ were higher in older adults, and that females had higher rates at older ages compared with males.

Table 4 presents the duration of CP for respondents who reported a pain severity of 5 or more during their last episode. While the largest number had been suffering from CP for more than 20 years, approximately $40 \%$ had been suffering from CP for between two and 10 years.

Table 5 presents the severity of pain reported by respondents during the most recent episode. While there was a decline in the number who reported higher severities, almost one-third of those who suffered from CP reported severity levels of 8,9 or 10 . 
TABLE 3

Prevalence of chronic pain in Canada according to age and sex (2007 to 2008)

\begin{tabular}{lll}
\hline Sex & Age, years & \% (95\% Cl) \\
\hline Female & 18 to 25 & $16.3(9.9-22.7)$ \\
26 to 35 & $17.4(13.3-21.5)$ \\
36 to 45 & $19.2(16.2-22.2)$ \\
& 46 to 55 & $23.4(20.4-26.3)$ \\
56 to 65 & $28.6(25.0-32.1)$ \\
66 and older & $31.5(28.1-34.8)$ \\
Male & 18 to 25 & $17.3(10.5-24.2)$ \\
& 26 to 35 & $15.3(11.5-19.1)$ \\
& 36 to 45 & $22.0(18.7-25.4)$ \\
& 46 to 55 & $22.8(19.7-25.9)$ \\
56 to 65 & $22.0(18.6-25.4)$ \\
& 66 and older & $22.2(18.6-25.8)$ \\
\hline
\end{tabular}

\section{TABLE 4}

Duration of pain in chronic pain sufferers

\begin{tabular}{lc}
\hline Duration & $\%(95 \% \mathrm{CI})$ \\
\hline $20+$ years & $22.5(19.9-25.1)$ \\
15 to $<20$ years & $8.0(6.1-10.0)$ \\
10 to $<15$ years & $16.2(13.8-18.6)$ \\
5 to $<10$ years & $19.6(16.8-22.3)$ \\
2 to $<5$ years & $21.3(18.5-24.0)$ \\
1 to $<2$ years & $8.7(7.1-10.4)$ \\
6 months to 1 year & $3.7(2.6-4.9)$ \\
\hline
\end{tabular}

\section{TABLE 5}

Severity rating of most recent episode for chronic pain sufferers

\begin{tabular}{lc}
\hline Severity* & $\%(95 \% \mathrm{Cl})$ \\
\hline 5 & $27.4(24.5-30.3)$ \\
6 & $19.7(17.3-22.1)$ \\
7 & $21.0(18.2-23.7)$ \\
8 & $19.4(16.7-22.2)$ \\
9 & $5.3(3.8-6.9)$ \\
10 & $7.2(5.7-8.8)$ \\
\hline
\end{tabular}

*Based on a scale from 0 to 10

Table 6 summarizes the most commonly reported primary body sites for CP. The lower back was, by far, the most frequent locus of CP among Canadian adults. Table 7 presents the corresponding data when multiple sites were tabulated. The lower back remained a locus of pain for the largest number of individuals; more than one-third of those suffering from CP experienced lower back pain.

Table 8 presents the most commonly reported causes of pain. Arthritis and joint pain were the most frequently mentioned causes of CP.

\section{DISCUSSION}

The current study, once again, demonstrates that $\mathrm{CP}$ is a frequent complaint among Canadian adults. However, it is unique among Canadian studies because, in line with previous recommendations (5-7), it uses a specific, detailed and sequential definition of CP (Table 1) that shows that the prevalence estimates declined as progressively more stringent criteria were applied. These data may provide insight into the different, often higher, prevalence estimates reported in other studies in which less-stringent definitions of CP have been used.

Overall, the prevalence estimates from the current study were comparable with, although slightly higher than, those reported for Canadians in large survey samples of the general population using a less precise definition of CP (18-21).
TABLE 6

Primary anatomical site of pain among chronic pain sufferers

\begin{tabular}{lc}
\hline Site & $\%(95 \% \mathrm{Cl})$ \\
\hline Back - lower back & $22.3(19.7-24.9)$ \\
Back - upper back & $9.5(7.5-11.6)$ \\
Knee & $9.5(7.6-11.4)$ \\
Leg & $7.2(5.6-8.9)$ \\
Head & $6.2(4.4-8.0)$ \\
Shoulder & $6.1(4.6-7.6)$ \\
Neck & $5.4(4.1-6.8)$ \\
Hip & $5.2(4.1-6.4)$ \\
Joints & $3.6(2.5-4.7)$ \\
Foot & $3.4(2.2-4.6)$ \\
Hand & $2.8(1.9-3.7)$ \\
Abdomen & $2.2(1.4-3.00)$ \\
Arm & $2.2(1.3-3.1)$ \\
Elbow & $1.8(0.4-3.2)$ \\
Stomach & $1.7(1.0-2.4)$ \\
Ankle & $1.6(0.8-2.3)$ \\
Chest & $1.5(1.0-2.0)$ \\
Entire/whole body & $1.2(0.6-1.8)$ \\
Bones & $1.2(0.6-1.7)$ \\
Wrist & $1.0(0.3-1.6)$ \\
\hline
\end{tabular}

\section{TABLE 7}

Anatomical sites of pain (multiple sites counted) among chronic pain sufferers

\begin{tabular}{lc}
\hline Site & $\%(95 \% \mathrm{Cl})$ \\
\hline Back - lower & $35.5(31.9-39.2)$ \\
Back - upper & $15.4(12.9-17.9)$ \\
Knee & $14.9(12.3-17.6)$ \\
Leg & $13.7(11.5-16.0)$ \\
Shoulder & $11.2(9.2-13.2)$ \\
Neck & $9.3(7.6-11.1)$ \\
Hip & $8.9(7.3-10.6)$ \\
Head & $8.0(6.0-10.1)$ \\
Foot & $5.8(4.3-7.4)$ \\
Arm & $5.3(3.9-6.7)$ \\
Hand & $4.5(3.3-5.7)$ \\
Joints & $4.3(3.0-5.5)$ \\
Ankle & $2.8(1.8-3.8)$ \\
Elbow & $2.7(1.2-4.2)$ \\
Abdomen & $2.5(1.7-3.3)$ \\
Stomach & $2.4(1.5-3.3)$ \\
Chest & $2.3(1.6-3.0)$ \\
Wrist & $1.6(0.8-2.4)$ \\
Bones & $1.4(0.9-2.0)$ \\
Entire/whole body & $1.2(0.6-1.8)$ \\
\hline
\end{tabular}

Furthermore, the estimated Canadian CP prevalence fell almost precisely at the overall mean reported using the identical survey questions and criterion for CP by Brevik et al (10), as well as at the median of the CP estimates for the European countries surveyed. Similarly, despite a slight difference in the methodology for determining the body site for pain, the rank ordering of sites was very similar to those from the Breivik et al study, although European subjects reported greater frequencies of head pain and joint pain than did Canadians. A similar rank ordering was also observed among self-reported causes of pain, most notably among the three largest causes of CP (arthritic pain, back and spine pain and pain due to trauma) even though both the method of collecting information and the method of classifying causes were different across the studies. 
As in all telephone surveys, the present study had limitations related to the self-reporting of health. These included the ability of subjects to accurately recall diagnostic labels as well as the frequency and timing of events (including health service use). Alternative methodologies including chart reviews, in-person interviews and physical examinations, while bypassing the issue of subject recall, have important limitations of their own including dramatically increased cost and additional sampling biases. The present study also presented an interesting methodological challenge related to the 2007 data collection cycle in which data on the number of residents of 'non-pain households' was not recorded. The oversight was corrected in the 2008 cycle and well established procedures were applied to allow data from both cycles to contribute to the results. Overall, the current study adds to the growing literature on CP prevalence both through the use of recognized population sampling methods and through replication of the essential elements of a large and well-constructed European study.

\section{CONCLUSION}

The present study adds to a growing consensus about the high prevalence of $\mathrm{CP}$ within adult populations in industrialized nations when the prevalence questions are carefully formulated and administered to large samples. Unfortunately, it also calls attention to the fact that a
TABLE 8

\section{Self reported causes of chronic pain among chronic pain} sufferers

\begin{tabular}{lc}
\hline Reported cause & $\%(95 \% \mathrm{Cl})$ \\
\hline Arthritic and joint pains & $36.2(33.0-39.4)$ \\
Spine pain including neck, thoracic and lower back & $20.4(18.0-22.9)$ \\
Trauma including osteoporosis, & $15.0(12.6-17.4)$ \\
Other pain syndromes & $6.0(4.6-7.5)$ \\
Nerve/neuropathic pain syndromes incl. post surgical & $4.6(3.4-5.9)$ \\
Headaches & $4.2(2.8-5.6)$ \\
Muscle pain syndromes including fibromyalgia & $3.5(2.3-4.6)$ \\
Abdominal and visceral pains including angina & $1.8(1.0-2.6)$ \\
No answer & $8.2(6.5-10.0)$ \\
\hline
\end{tabular}

substantial proportion of Canadian adults live with CP that is longstanding and severe.

FUNDING: Funding for the current project was provided by a grant from the Canadian Pain Society

\section{APPENDIX A: SHORT SURVEY}

Hello, my name is from Nanos Research. We are conducting important health care research on issues related to pain, and we would like to include your opinions. May I ask you some background questions to determine if you qualify for our study?

S1. Your opinions will remain confidential, would you have three to four minutes to answer a few questions?

Yes........................ 1

No. . . . . . . . . 2 THANK AND TERMINATE

S2. First of all, are you 18 years of age or older?

Yes............. 1

No. . . . . . . 2 [ASK TO SPEAK TO SOMEONE OVER 18 AND REQUALIFY]

S3. How many adults aged 18 or older live in your household? Record Number

S4. How many adults aged 18 or older who live in your household have experienced pain from an illness, accident or medical condition? Record Number___ Adults 18+ who ever have experienced pain. IF "O" THANK AND TERMINATE TRACK AS A "NO PAIN" HOUSEHOLD

S5. Do you consider yourself someone who suffers from pain from an illness, accident or medical condition?

Yes ............ 1

No. . . . . . . . 2 ASK TO SPEAK TO THAT HOUSEHOLD MEMBER

OVER 18 REPEAT INTRODUCTION AND CONFIRM QU. S5 = YES CONTINUE SCREENING THE HOUSEHOLD MEMBER WHO SUFFERS FROM PAIN

S6. Record gender from voice

Male ........... 1

Female......... 2

S7. How old were you on your last birthday? Record Age __ Years old

TERMINATE IF LESS THAN 18 YEARS OLD

S8. For how long have you suffered from pain due to your illness, accident or medical condition? Years or Months or Weeks

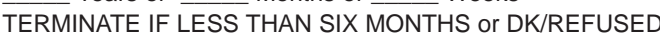

S9. When was the last time you experienced pain? Was it...? (READ LIST) (ACCEPT ONE RESPONSE)

Today .................... 1 CONTINUE

Not today, but within the past week .......2 CONTINUE

More than a week, but less than a month ago. 3 CONTINUE

1-3 Months ago .............4 THANK AND TERMINATE

4-6 Months ago $\ldots \ldots \ldots \ldots \ldots \ldots \ldots \ldots$ THANK AND TERMINATE

DK/Refused 77 THANK AND TERMINATE

S10. How often do you experience pain? Do you experience it...? (READ LIST) (ACCEPT ONE RESPONSE)

At all times (for example...night and day) . . 1 CONTINUE

Daily........................2 CONTINUE
Several times a week. . . . . . .............. CONTINUE

Approximately once a week ..........4 THANK AND

TERMINATE

Several times a month . . . . . . . . . . 5 THANK AND

TERMINATE

Approximately once a month . . . . . . 6 THANK AND

TERMINATE

Less often than once a month $\ldots \ldots \ldots \ldots \ldots 7$ THANK AND

TERMINATE

DK/Refused . . . . . . . . . . . . 77 THANK AND

TERMINATE

S11. Thinking about the last time you experienced pain, please give me a number from 0 to 10 to indicate the intensity of your pain. Please use a scale where a "0" means "no pain at all" and a "10" means "the worst pain imaginable." (DO NOT READ LIST) (ACCEPT ONE RESPONSE ONLY)

0 No pain at all ......... 0 THANK AND TERMINATE

$1 \ldots \ldots \ldots \ldots \ldots \ldots$ THANK AND TERMINATE

$2 \ldots \ldots \ldots \ldots \ldots \ldots \ldots$ THANK AND TERMINATE

$3 \ldots \ldots \ldots \ldots \ldots \ldots \ldots . \ldots \ldots$ THANK AND TERMINATE

$4 \ldots \ldots \ldots \ldots \ldots \ldots \ldots$ GO TO S12

$5 \ldots \ldots \ldots \ldots \ldots \ldots \ldots \ldots$

$6 \ldots \ldots \ldots \ldots \ldots \ldots \ldots 6$ SKIP TO S13

$7 \ldots \ldots \ldots \ldots \ldots \ldots \ldots \ldots$

$8 \ldots \ldots \ldots \ldots \ldots \ldots$ SKIP TO S13

$9 \ldots \ldots \ldots \ldots \ldots \ldots$ SKIP TO S13

10 The worst pain imaginable 10 SKIP TO S13

11 DK/Refused.......... 77 THANK AND TERMINATE

S12. Is the reason for the pain score because of effective treatment? Yes............... CONTINUE

No................. 2 THANK AND TERMINATE

S13. Where is your pain located?

(DO NOT READ LIST) (ACCEPT MULTIPLES)

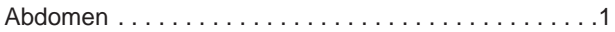

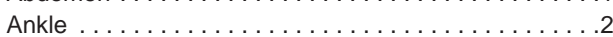

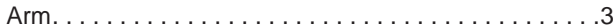

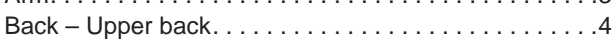

Back - Lower back. . . . . . . . . . . . . . . . . . . . . . . . 5

Bladder. . . . . . . . . . . . . . . . . . . . 6

Bones. . . . . . . . . . . . . . . . . . . . . . . .

Chest . . . . . . . . . . . . . . . . . . . . . . . . .

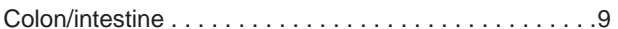

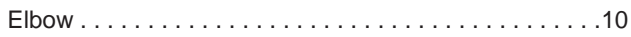

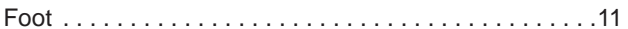

Groin. . . . . . . . . . . . . . . . . . . . . . . 12

Hand. . . . . . . . . . . . . . . . . . . . . . 13

Head. . . . . . . . . . . . . . . . . . . . . . . . . . . . . . . . . . .

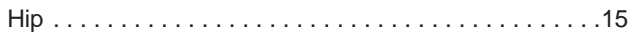

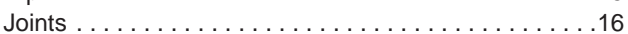

Knee. . . . . . . . . . . . . . . . . . . . . . . 17

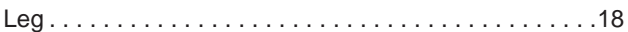




\section{APPENDIX: SHORT SURVEY - CONTINUED}

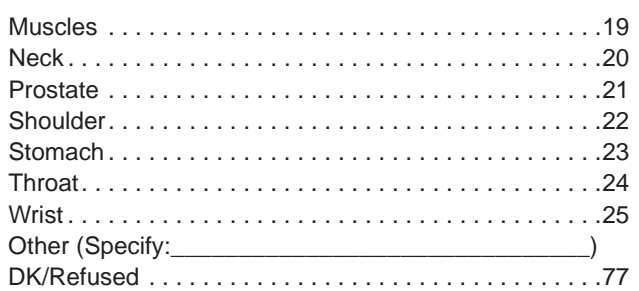

S14. Please tell me all the illnesses or medical conditions that are the cause of your pain. (DO NOT READ LIST) (ACCEPT MULTIPLES) - OVERCODE FOR MULTIPLE CAUSES

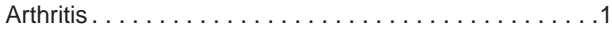

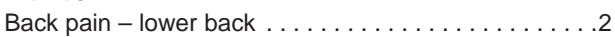

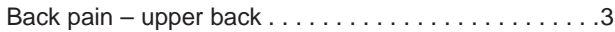

Back pain - deterioration of spine . . . . . . . . . . 4

Bursitis . . . . . . . . . . . . . . . . . . . . . . . . . . . . . . . . .

Bone spurs. . . . . . . . . . . . . . 6

Broken bone or fracture that never healed properly $\ldots 7$

Cancer ......................

Cartilage damage . . . . . . . . . . . . . . . . . . . . . . . . .

Crohn's Disease . . . . . . . . . . . . . . . . . . 10

Diabetic neuropathy . . . . . . . . . . . . . . . . 11

Disc problems (herniated/deteriorated) . . . . . . . . 12

Diverticular disease - (diverticulitis/diverticulosis) . . . .13

Endometriosis. . . . . . . . . . . . . . . . . . . 14

Fibromyalgia. . . . . . . . . . . . . . . . . . . . . . 15

Headaches/migraine . . . . . . . . . . . . . . 16

Headaches - Migraine . . . . . . . . . . . . . . . . . . . . . . . . . . . . . . . .

Headaches - Cluster . . . . . . . . . . . . . . . . . . . . . . . . . . . . . . .

Headaches - Chronic daily. . . . . . . . . . . . . . . . 19

Headaches - Post traumatic or cervicogenic . . . . . . . 20

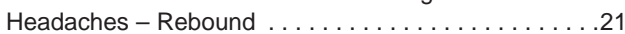

Hip - bad hip . . . . . . . . . . . . . . . . . 22

Hip - old break. . . . . . . . . . . . . . . . . . . . . . . . . . . .

Hip - hip replacement . . . . . . . . . . . . . . . . . . . . . . . . . . . . . .

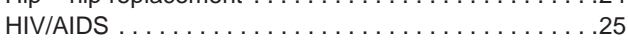

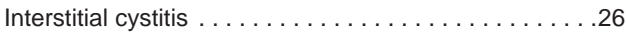

Irritable bowel. . . . . . . . . . . . . . . . . 27

Joints, generally . . . . . . . . . . . . . . . . . . 28

Knees - bad knees . . . . . . . . . . . . . . . 29

\section{REFERENCES}

1. Henry JL. The need for knowledge translation in chronic pain. Pain Res Manage 2008;6,465-76.

2. Brennan F, Carr DB, Cousins M. (2007) Pain management: A fundamental human right. Anesth Analg 2007;105:205-21.

3. Lohman D, Schleifer R, Amon JJ. DEBATE Open access to pain treatment as a human right. BMC Medicine 2010;8:8.

4. Dobkin PL, Boothroyd LJ. Organizing health services for patients with chronic pain: when there is a will there is a way. Pain Med 2008;9:881-9.

5. Verhaak PFM, Kerssens JJ, Dekker J, Sorbi MJ, Bensing JM. Prevalence of chronic benign pain disorder among adults: A review of the literature. Pain 1998;77:231-9.

6. Nickel R, Raspe HH. Chronischer Schmerz: Epidemiologie und Inanspruchnahme. Nervenarzt 2001;72:897-906.

7. Ospina M, Harstall C. Prevalence of Chronic Pain: An Overview. Alberta Heritage Foundation for Medical Research, Health Technology Assessment. Report No. 28 , 2002. Edmonton, AB.

8. International Association for the Study of Pain. Classification of chronic pain. Descriptions of chronic pain syndromes and definitions of pain terms. Pain 1986;(Suppl 3):S1-S225.

9. Schopflocher D, Harstall C. The Descriptive Epidemiology of Chronic Pain. In: Rashiq S, Schopflocher D, Taenzer P, eds. Chronic Pain: A Health Policy Perspective, In: Jonsson E (Series Editor) Health Care And Disease Management Series. Weinheim: John Wiley, 2008.

10. Brevik H, Collett B, Ventafridda V, Cohen R, Gallacher D. Survey of chronic pain in Europe: Prevalence, impact on daily life, and treatment. Eur J Pain 2006;10:287-333.

11. Demyttenaere K, Bruffaerts R, Lee S, et al. Mental disorders among persons with chronic back or neck pain: Results from the world mental health surveys. Pain 2007;129:332-42.

12. Crook J, Rideout, E, Browne G. The prevalence of pain complaints in a general population. Pain 1984;18:299-314.

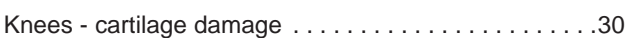

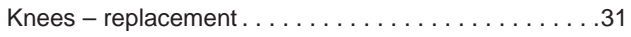

Lupus . . . . . . . . . . . . . . . . . . . . . . . .32

Medication reactions $\ldots \ldots \ldots \ldots \ldots \ldots \ldots \ldots \ldots$

MS/Multiple Sclerosis. . . . . . . . . . . . . . . . . . . . . 34

Muscular dystrophy . . . . . . . . . . . . . . . . 35

Neck pain . . . . . . . . . . . . . . . . . . .36

Neuropathy (unspecified) . . . . . . . . . . . . . . . . 37

Nerve damage/pain . . . . . . . . . . . . . . . . . . . . . . . . . . . . . . . .

Osteoarthritis . . . . . . . . . . . . . . . . . . . . 39

Osteoporosis . . . . . . . . . . . . . . . . . . 40

Poor circulation/vascular disease. . . . . . . . . . . . .41

Post-herpetic neuralgia (Shingles pain) . . . . . . . . . . . . . . . . . . . . . .

Radiation or chemotherapy . . . . . . . . . . . . . 43

Repetitive Motion/carpal tunnel syndrome/Tendonitis . .44

Rheumatoid Arthritis. . . . . . . . . . . . . . . . . . . . . . . 45

Sciatica. . . . . . . . . . . . . . . . . . . . . . . . . . . . . . . . . . .

Scoliosis . . . . . . . . . . . . . . . . . . . . . . . . . . . . .47

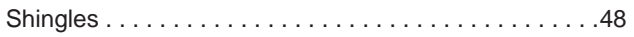

Shoulder injury . . . . . . . . . . . . . . . . . . . . . . .49

Shoulder replacement . . . . . . . . . . . . . . 50

Shoulder - torn rotator cup . . . . . . . . . . . . . . 51

Spinal Stenosis . . . . . . . . . . . . . . . . . 52

Surgical pain/post op . . . . . . . . . . . . . . . . . . . . . . . . . .

Trigeminal Neuralgia . . . . . . . . . . . . . . . . . . .54

Traumatic injury . . . . . . . . . . . . . . . . . . . . . . . . . . . . . . . . . . . . . .

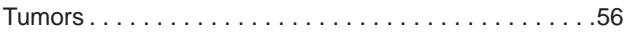

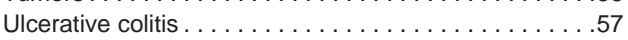

Whiplash. . . . . . . . . . . . . . . . . . . . 58

$\mathrm{XX} \ldots \ldots \ldots \ldots$ Other (Specify

DK/Refused . . . . . . . . . . . . . . . . . . 77

S15. Thank you for your responses.

You qualify to complete a survey on chronic pain. It will take approximately 20-30 minutes[check against actual] depending on your answers, and we will mail you a cheque for \$20 in appreciation for your time. Would you be interested in sharing your views for the more detailed survey? Our objective is to help medical researchers better understand pain suffering in Canada.

Yes .... 1 ADMINISTER IMMEDIATELY OR SCHEDULE INTERVIEW No..... 2 THANK AND TERMINATE

13. Birse EM, Lander J. Prevalence of chronic pain. Can J Public Health 1998;89:129-31.

14. Moulin DE, Clark AJ, Speechley M, Morley-Forster MK. Chronic Pain in Canada - prevalence, treatment, impact and the role of opioid analgesia. Pain Res Manag 2000;7:179-84.

15. Boulanger A, Clark AJ, Squire P, Cui E, Horbay GLA. Chronic Pain in Canada: Have we improved our management of chronic noncancer pain? Pain Res Manag 2004;12:39-47.

16. Tripp DA, VanDenKerkhof EG, McAlister M. Prevalence and determinants of pain and pain-related disability in urban and rural settings in southeastern Ontario. Pain Res Manag 2006;11:225-33.

17. Feeny D, Furlong W Boyle M, Torrance GW. Multi-attribute health Status classification systems: Health Utilities Index. PharmacoEconomics 1985;7:490-502.

18. Millar WJ. Chronic Pain. Health Reports 1996;7:47-53.

19. Schopflocher DP. Chronic pain in Alberta: A portrait from the 1996 National Population Health Survey and the 2001 Canadian Community Health Survey. Alberta Health and Wellness Public Report, Edmonton: Alberta Health and Wellness, 2003.

20. VanDenKerkhof EG, Hopman WM, Towheed TE, Anastassiades TP, Goldstein DH. The impact of sampling and measurement on the prevalence of self-reported pain in Canada. Pain Res Manag 2003;8:157-63.

21. Rashiq S, Dick BD. Factors associated with chronic noncancer pain in the Canadian population. Pain Res Manag 2009;14:454-60.

22. Statistics Canada, (2008) Canada's population estimates. <www.statcan.gc.ca/daily-quotidien/090326/dq090326a-eng.htm> (Accessed on June 16, 2011).

23. Yeo D, Mantel H, Liu T-P. Bootstrap variance estimation for the National Population Health Survey, proceedings of the survey research methods section, American Statistical Association, 1999. <www.amstat.org/Sections/Srms/Proceedings/papers/1999_136.pdf> (Accessed on May 12, 2010). 


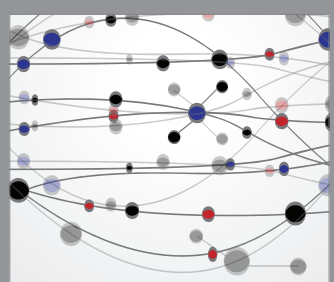

The Scientific World Journal
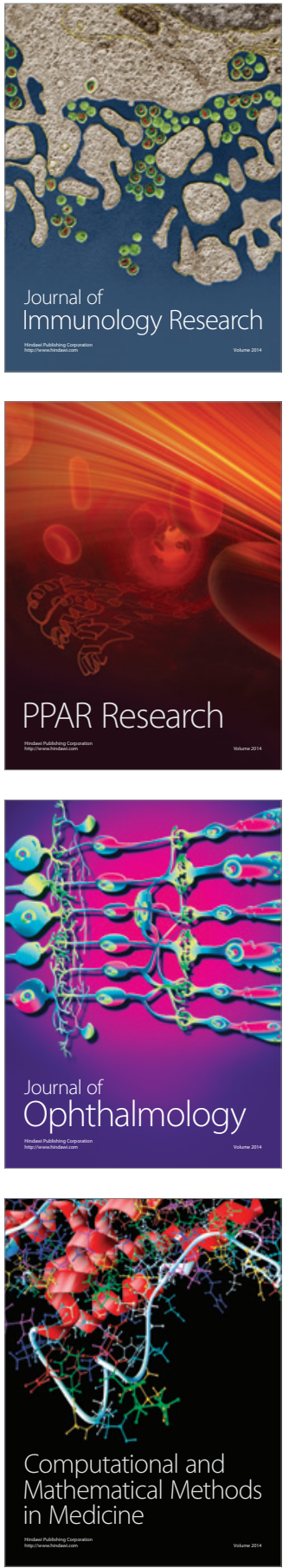

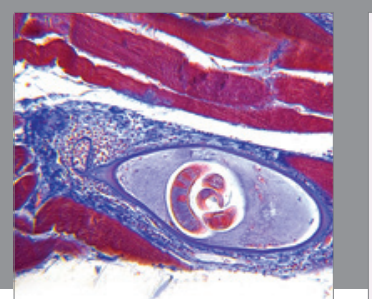

Gastroenterology Research and Practice

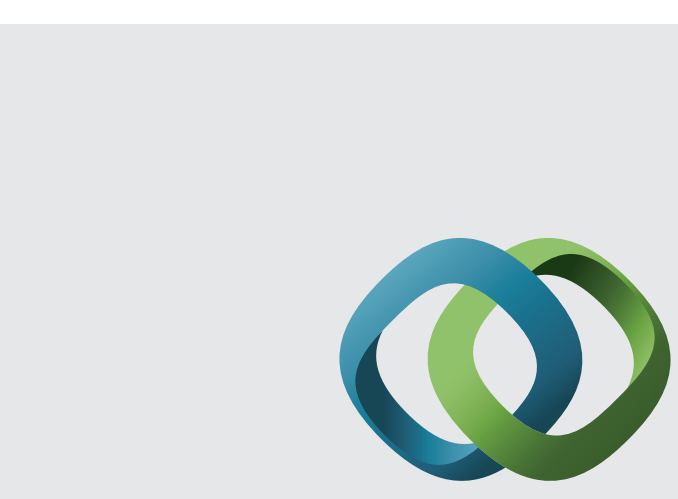

\section{Hindawi}

Submit your manuscripts at

http://www.hindawi.com
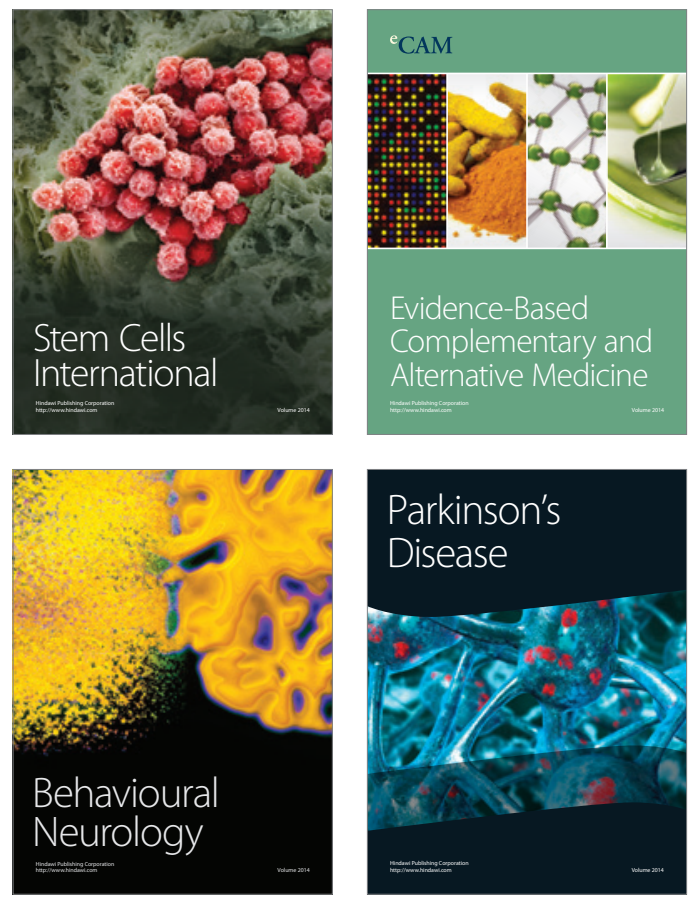
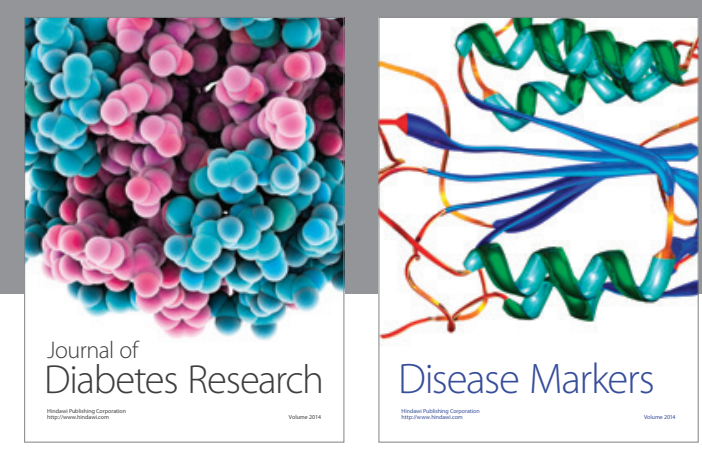

Disease Markers
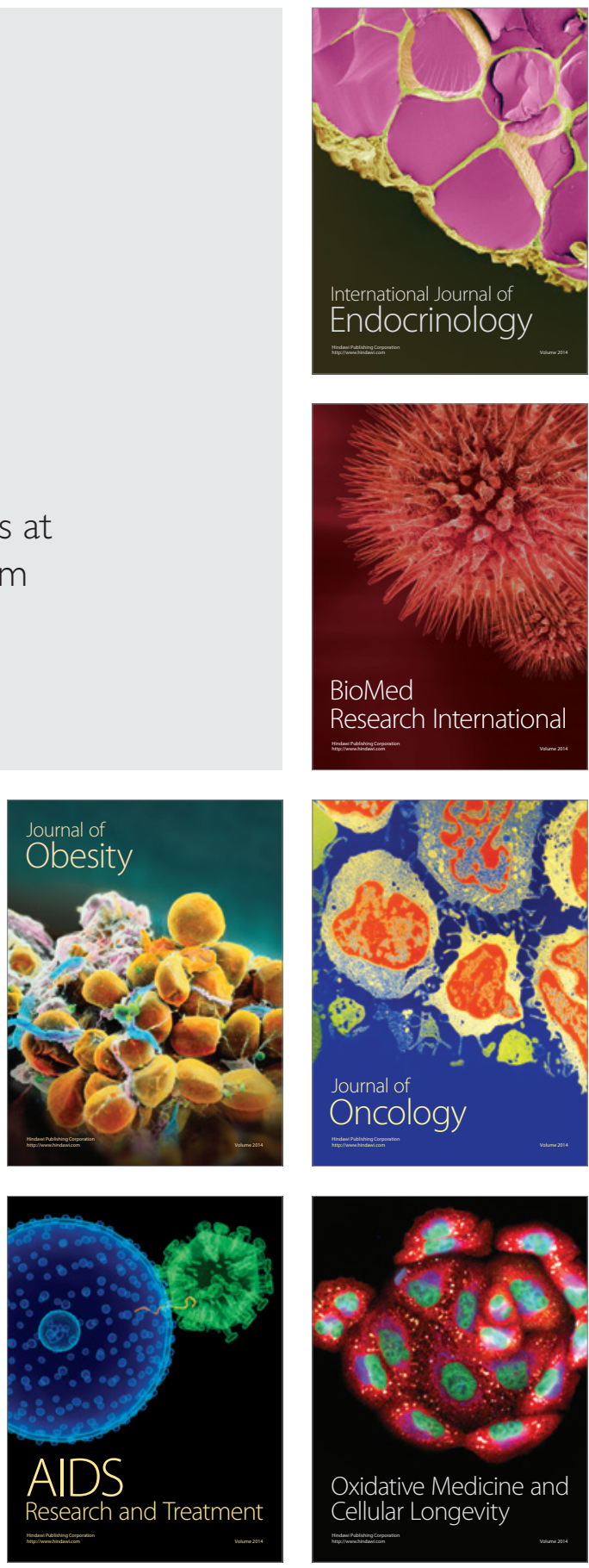